\title{
Barriers and Strategies to Prevent HIV/AIDS among Pacific Countries: A Systematic Review Study
}

\author{
Masoud Mohammadnezhad ${ }^{*}$, Julie Qilabasa Alakalia², Tamara Mangum ${ }^{3}$, \\ Falakika Pasikala Fetuu ${ }^{4}$, Joshua Jeffrey Lucas $^{5}$
}

${ }^{1}$ Discipline of Health Promotion, Department of Public Health \& Primary Health Care, Fiji National University, Suva, Fiji

${ }^{2}$ Department of Public Health, Ministry of Health, Honiara, Solomon Islands

${ }^{3}$ Discipline of Emergency Health Management, Department of Public Health \& Primary Health Care, Fiji National University, Suva, Fiji

${ }^{4}$ Department of Nursing, Ministry of Health, Nuku'alofa, Tonga

${ }^{5}$ Department of Public Health, Ministry of Health, Weno, Federated States of Micronesia

Email: *masoud.m@fnu.ac.fj

How to cite this paper: Mohammadnezhad, M., Alakalia, J.Q., Mangum, T., Fetuu, F.P. and Lucas, J.J. (2017) Barriers and Strategies to Prevent HIV/AIDS among Pacific Countries: A Systematic Review Study. Advances in Sexual Medicine, 7, 20-33.

http://dx.doi.org/10.4236/asm.2017.71002

Received: December 9, 2016

Accepted: December 26, 2016

Published: December 29, 2016

Copyright $\odot 2017$ by authors and Scientific Research Publishing Inc. This work is licensed under the Creative Commons Attribution International License (CC BY 4.0).

http://creativecommons.org/licenses/by/4.0/

\section{Abstract}

Introduction: While the prevalence of HIV/AIDS is shown to be decreasing in the last few decades, it still remains a serious public health issue in Pacific countries. This study is aimed to review the common barriers and also preventive strategies for HIV/AIDS among Pacific Islanders. Methodology: This systematic review study on HIV/AIDS was developed based on the Cochrane Library Guideline. Seven online databases which were more frequently used in finding relevant studies were used to search literatures. Using relevant key words, all studies found in the search were reviewed by two independent reviewers and their quality and relevance were assessed. All previous qualitative and quantitative published articles included in the study were published from 2000 to 2016 and in the English language. A data extraction sheet was developed and a descriptive statistic was used to analyze the data. Results: Twenty-two studies met the study inclusion and exclusion criteria. Many of the studies were conducted in American Pacific countries (50\%). Community-based studies were the most common type of studies (72.7\%). In quantitative studies, the most common barriers were lack of accessibility to health services and lack of knowledge, while in the qualitative studies they were cultural barriers and access to health services. Educational trainings on sexual health topics were identified as the main preventive strategy. Conclusion: This study highlights the main barriers of HIV/AIDS among Pacific Islanders. It also provides a guide for decision makers to develop and implement new strategies which are sensitive and based on Pacific cultures and beliefs.

\section{Keywords}

HIV/AIDS, Barriers, Preventive Strategies, Pacific Islanders 


\section{Introduction}

The human immunodeficiency virus (HIV) has become one of the leading causes of death around the globe today [1]. HIV causes acquired immune deficiency syndrome (AIDS) and attacks the body's immune system. This deadly disease claims many lives each year and is said to be more common in low and middle income countries [2]. Globally, the figure of people currently living with HIV/AIDS in 2015 was estimated to be more than 35 million [3]. According to the United Nations program for HIV/AIDS (UNAIDS) in 2016, out of that estimated more than 35 million, 19 million of them were from eastern and southern Africa, 6.5 million from western and central Africa, 5.1 million from Asia and the Pacific, 2.4 million from Western and central Europe and North America, while Latin America and the Caribbean accounted for 2 million cases, eastern Europe and central Asia had 1.5 million and 230,000 cases were from the Middle East and northern Africa [4]. The World Health Organisation also reported that HIV/AIDS accounted for the death of 1.1 million people in 2015 [5]. Even though there is no cure for HIV/AIDS, it can still be prevented [3].

Moreover, HIV barriers can be seen as a factor which has contributed to the rise of HIV/AIDS globally [6]. In Africa, some of the barriers are economic barriers, social and cultural barriers and legal barriers [7]. While in China, stigma and punitive barriers are barriers which prevent HIV identification [8]. In comparison to Europe, perceptions of patients and attitude of health care providers are barriers [9]. In the Pacific, cultural barriers, access to health services, stigma and cost of medication were recognized as common barriers for HIV patients in Papua New Guinea (PNG), Vanuatu and Pacific Islanders in America [10] [11] [12].

Even though HIV/AIDS cannot be cured it can still be treated so the only way to lessen the number of HIV/AIDS patients is to have some preventive strategies [13]. There are different methods of HIV/AIDS prevention. The most common strategies include: attempting to postpone the onset of first intercourse, reducing the number of sexual partners, increasing the number of sexual protective activities, offering counselling and testing for HIV, encouraging adherence to biomedical approaches avoiding HIV transmission, reducing sharing of needles, and syringes and decreasing substance use [14]. In Africa, their preventive strategies are condoms, prevention of mother to child transmission, voluntary medical male circumcision, harm reduction and antiretroviral treatment [15]. In the United States, some of their strategies are: programs to combat stigma and discrimination, increased open communication about sexual activities, multi-sectorial approaches and STI surveillance and control [16]. In the United Kingdom, prevention programs for MSM, harm reduction, HIV awareness and prevention programs for Africans who settle in UK are some of their preventive strategies [17]. Whereas in China there is prevention of infected blood donation and transfusion practices in place [18]. In the Pacific, there is increased awareness, health education, vaginal micro biocide and distribution of condoms in PNG, Vanuatu, Federated States of Micronesia (FSM), Fiji, Tonga, Samoa, Hawaii and American Pacific Islanders [19]-[24].

From the literature reviews carried out by now, no systematic reviews have been done on HIV/AIDS in the Pacific. This systematic review aims to identify the barriers and strategies of HIV/AIDS prevention in the Pacific region. This will help fill the gap 
and help health workers in the Pacific create the best health promotion strategies which can help combat and lessen the number of HIV/AIDS patients among Pacific Islanders.

\section{Methods}

This systematic review study was developed according the Cochrane Library Guideline. To achieve a broad spectrum of the HIV/AIDS related barriers among Pacific Islanders, both qualitative and quantitative studies were considered. To prevent potential barriers in selecting the articles and extracting the relevant results, and also analyzing and interpreting the results, two independent reviewers were used. They discussed any issues encountered in any stage of review and they discussed the issues with the other authors to get an agreement.

Considering previous studies conducted in the field of HIV/AIDS, seven online databases, which were more frequently used in finding relevant studies, were used including: MEDLINE/PubMed, CINAHL, ISI Web of Science, EBSCO, ProQuest, Springer and PyschInfo. Different keywords were used to find relevant articles. They were "barriers" AND "strategy" and "policy" AND "intervention".

Any articles published in any online peer-reviewed journals between $1^{\text {st }}$ January 2010 and $1^{\text {st }}$ August 2016 were included in the study. This time period was chosen as we were able to review the recently published studies and also look at new insights on appropriate preventive strategies towards HIV/AIDS which are applicable for Pacific islanders. Moreover, articles were considered if they were conducted among both males and females, all age groups, were in the English language, and focused on Pacific countries. In this study, barriers of HIV/AIDS can be considered as: all individual, social, cultural, and organizational obstacles which restrict people's knowledge of HIV prevention, access to healthcare systems, doing HIV testing, and also to treatment of HIV. Studies focused on HIV/AIDS determinants or prevalence were excluded.

A narrative search was implemented in three stages. First, the abstracts of all researched articles were scanned and those that were not relevant or were duplicated were excluded from the first stage. The abstract of the remaining articles were reviewed and some articles were omitted at this stage if they didn't meet the study inclusion and exclusion criteria. At the last stage, the full text of all remaining articles was printed and reviewed to assess their quality. Another search was conducted on the bibliographies of the remaining articles to locate other unpublished article titles. The additional search was performed using various Internet resources.

A data extraction sheet was made to include all relevant information needing to be analyzed. They included the article's characteristics (the year published, country of the study, type of study), participants characteristics (age, gender, number), methodology (data collection tools, sampling method, place of the study), and the results. Overall, 17 studies met the study inclusion and exclusion criteria. The search process is shown in Figure 1.

In addition, we found another 5 articles in the bibliography of the remaining articles. Finally, 22 studies were reviewed in this study.

A descriptive analysis was applied to analyze the data. The results were reported as percentages and frequencies using tables and graphs. 


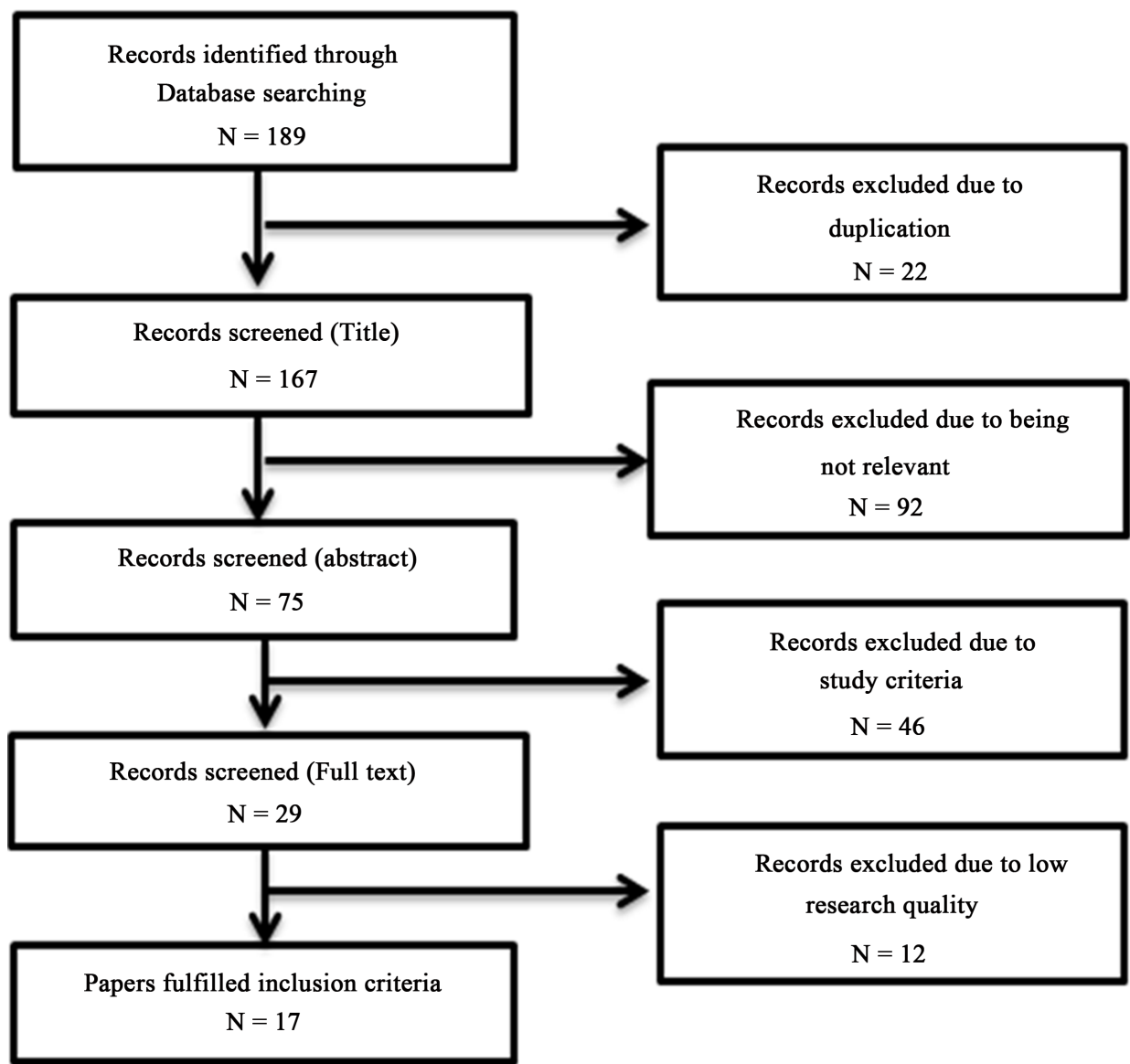

Figure 1. Article selection process.

\section{Results}

The general characteristics of the studies are shown in Table 1. Many studies were conducted after 2010 (54.5\%). Half of the studies were conducted in American Pacific countries. Four studies (18.2\%) were conducted among only males, however, many studies did not report the gender of target groups (45.5\%).

The results of the studies showed that the United Sates had the highest number of studies about HIV/AIDS (11 studies), followed by Papua New Guinea (5 studies), Vietnam (4 studies), and Vanuatu and Thailand ( 3 studies each). The study results revealed that many were studies conducted among Adolescents/Adults (31.8\%), however, 40.9\% didn't report the age of participants. The results also showed that the pooled number of participants in the studies was 26,641 people. The study also showed that most of the studies focused on Gay/Men who have Sex with Men (5 studies) and health care workers ( 5 studies) as target groups, followed by HIV patients (3 studies), female sex workers ( 3 studies), and young adults $\&$ parents ( 3 studies).

As Table 2 shows, a majority of the studies applied quantitative methodology (45.5\%). Ten studies used questionnaires to collect the data. Purposive sampling (50\%) was the most common sampling method.

As Figure 2 shows, the majority of studies were community based studies $(72.7 \%)$ followed by school based studies (18.2\%) and health care center-based studies $(9.1 \%)$. 
Table 1. General characteristics of the studies $(\mathrm{N}=22)$.

\begin{tabular}{ccc}
\hline Variables & Frequency & Percentage \\
\hline Year & 2 & \\
$2000-2004$ & 8 & 9.1 \\
$2005-2009$ & 12 & 36.4 \\
$2010<$ & & 54.5 \\
Region & 6 & 27.3 \\
South Pacific & 11 & 50 \\
American Pacific & 5 & 22.7 \\
Asia-Pacific & & 18.2 \\
Targeted gender & 4 & 13.6 \\
Male & 3 & 13.6 \\
Female & 3 & 4.5 \\
Male/Female & 1 & 4.5 \\
Female/Male/Transgender & 1 & 45.5 \\
Male/Heterosexual & 10 & \\
Unknown & &
\end{tabular}

Table 2. Methodological characteristics of studies $(\mathrm{N}=22)$.

\begin{tabular}{|c|c|c|}
\hline Variables & Frequency & Percentage \\
\hline \multicolumn{3}{|l|}{ Type of studies } \\
\hline Quantitative studies & 10 & 45.5 \\
\hline Qualitative studies & 11 & 50 \\
\hline Mixed method study & 1 & 4.5 \\
\hline \multicolumn{3}{|l|}{ Data collection tools } \\
\hline Questionnaire & 10 & 45.5 \\
\hline In depth interview & 4 & 18.1 \\
\hline Focus group discussion & 6 & 27.3 \\
\hline Questionnaires and screening & 1 & 4.5 \\
\hline Test & 1 & 4.5 \\
\hline \multicolumn{3}{|l|}{ Unknown } \\
\hline \multicolumn{3}{|l|}{ Sampling methods } \\
\hline Convenience & 4 & 18.1 \\
\hline Snowball & 5 & 22.7 \\
\hline Purposive & 11 & 50 \\
\hline Random & 1 & 4.5 \\
\hline Stratified & 1 & 4.5 \\
\hline
\end{tabular}




\section{7}

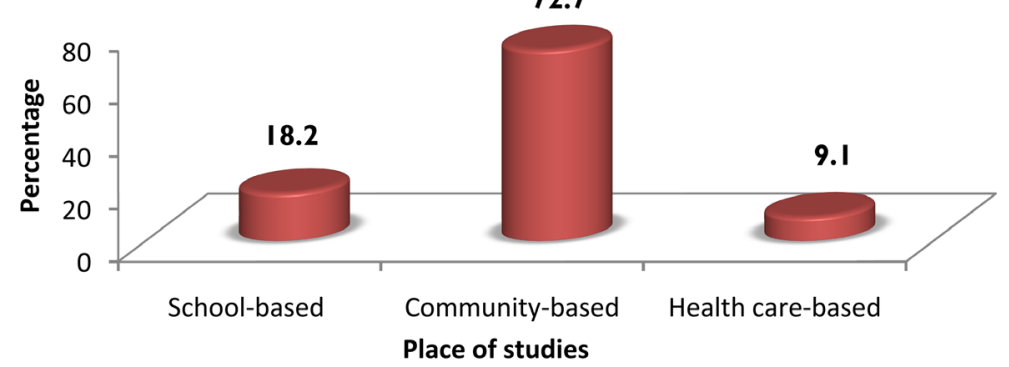

Figure 2. Frequency of studies based on the conducted place.

\section{Barriers of HIV/AIDS among patients}

Out of 22 studies, 8 quantitative studies highlighted the barriers of HIV/AIDS among Pacific Islanders. The most common barriers have been recognised as lack of accessibility to health services ( 3 studies, 37.5\%), followed by lack of knowledge ( 2 studies, $25 \%$ ). The cultural taboos and ethnicity have been recognised as the least barriers among $\mathrm{Pa}$ cific Islanders (1 study each).

Out of 22 reviewed articles, 10 qualitative studies focused on barriers. The most common barriers were cultural barriers ( 5 studies, $50 \%$ ), followed by access to health services (3 studies, 30\%) among Pacific Islanders. The least barriers were racism and lack of sex education (1 study each).

\section{Strategies to prevent HIV/AIDS}

Out of 11 quantitative studies, 3 mentioned strategies to prevent HIV/AIDS. Two out of the 3 studies found educational training on sexual health topics to be the main strategy, followed by diagnostic prevention, including the symptoms of HIV/AIDS (1 study).

Only one qualitative study suggested using preventive methods such as intravaginal practices (vaginal microbicides) as a strategy to prevent HIV.

\section{Discussion}

From the results, this study recognized culture as one of the common barriers, which may have contributed to HIV/AIDS in the Pacific [21] [25]. In the Pacific, culture can be seen as one of the essentials to maintaining national, ethnic or group identity [26]. Culture becomes a barrier in a sense that it will be considered culturally inappropriate for parents to openly discuss sexual health with their children [27] [28]. Sexual health is a very sensitive topic and it cannot be openly discussed within the family and community as this will not be acceptable in the Pacific culture [28]. In 2011 a study done in Africa [29], and another done in China, [30], it was highlighted that sex related topics are still seen as a taboo subject in the respective cultures and is hardly discussed openly by most African or Chinese families.

Another barrier among Pacific Islanders identified in this study was access to health services [11]. One reason is geographical locations as the islands are scattered so the remote places cannot easily gain access to health services because they live far from the health centres [10]. Another reason would be that services provided in the urban hospitals vary from health services available in rural health centres due to hospitals being 
more advanced than rural health centres [31]. As further discussed by Silal et al., (2012) [32], in Africa, lack of transportation, long hours of travel and remote areas do not have good access to health services compared to urban centres. Cost of medications could be another possible factor, only allowing people with high economic status to have access to good health services [11]. This is because Pacific islands are still developing countries and the hospitals have limited resources available, compared to private clinics which have more advanced technologies to detect diseases quickly [33]. This is common in low income countries in the Pacific where people with high economic status have better access to good health care [34], compared to a study done among American Pacific Islanders in America which showed people with low economic status do not have access to good health care and those with high economic status have access to good health care [35].

The study also identified stigma as another barrier being faced by those people living with HIV/AIDS [36]. According to Jenkins, stigma becomes a barrier to HIV testing as it hinders people to go for HIV testing because they fear their families, friends and everyone will reject them if they have HIV/AIDS, as supported by Kang et al. (2006) [37]. Meiberg, et al. (2008) also added that stigma is also a barrier to voluntary HIV testing and counselling in South Africa [38].

Prevention is better than cure, so the best strategy to fight HIV is to prevent it [39]. From this study, many of the studies pointed out the common strategy which has been practiced is educational trainings or awareness. As further explained by Ramos et al. (2009) [40], health education is the best strategy which can be successfully implemented and easily carried out by any health worker. Another recommended prevention method is vaginal microbiocide. Vaginal microbiocide is a safe and effective prevention method for HIV and STIs because it can help kill and neutralize viruses and bacteria, and is said to decrease the chances of HIV by $27 \%$ [19] [41].

Most of the studies reviewed were conducted after 2010, showing that many researchers have gotten interested in studying HIV/AIDS recently. Most of the studies reviewed were descriptive, followed by retrospective and cross-sectional, but lack interventional studies, which were said to provide the most reliable evidence [42].

Furthermore, as shown from the results, $68.2 \%$ of the studies were conducted in the community and only $18.2 \%$ of the studies were conducted in schools. More studies should have been conducted in schools to provide information on HIV/AIDS to adolescents as they tend to engage in sexual behaviours and other risk behaviours, so as to help prevent the increase of HIV in the future [43]. In addition, purposive sampling method was mainly used but randomized control sampling is preferable because it gives quality results and reduces bias [44].

Therefore, as shown in our results, culture is the most common barrier, followed by access to health services and stigma. To address the previously stated barriers, interventions need to be done. Thus, the best strategy to address cultural barriers is to conduct health education regarding HIV based on different genders. Health services and health workers should reach out to people who cannot access health services. The result of this study provides a guide for policy makers to develop and implement new strategies which are sensitive and based on Pacific cultures and beliefs. 
A limitation in this study was that only English language publications were searched for. This may affect accessibility to other valuable studies that were published in languages other than English.

\section{References}

[1] Glassner, B. (2010) The Culture of Fear: Why Americans Are Afraid of the Wrong Things: Crime, Drugs, Minorities, Teen Moms, Killer Kids, Mutant Microbes, Plane Crashes, Road Rage, \& So Much More. Basic Books, New York.

[2] Mathers, C.D. and Loncar, D. (2006) Projections of Global Mortality and Burden of Disease from 2002 to 2030. PLOS Medicine, 3, e442. https://doi.org/10.1371/journal.pmed.0030442

[3] Deeks, S.G., et al. (2016) International AIDS Society Global Scientific Strategy: Towards an HIV Cure 2016. Nature Medicine, 22, 839-850.

[4] UNAIDS (2016) Joint United Nations Programme on HIV/AIDS. http://www.unaids.org/sites/default/files/media asset/global-AIDS-update-2016 en.pdf

[5] HIV/AIDS (UNAIDS) (2008) Report on the Global Acquired Immunodeficiency Syndrome Epidemic.

[6] Govender, R. (2005) The Barriers and Challenges to Health Promotion in Africa. South African Family Practice, 47, 39-42. https://doi.org/10.1080/20786204.2005.10873303

[7] Mahande, M.J., Phimemon, R.N. and Ramadhani, H.O. (2016) Factors Associated with Changes in Uptake of HIV Testing among Young Women (Aged 15 - 24) in Tanzania from 2003 to 2012. Infectious Diseases of Poverty, 5, 92. https://doi.org/10.1186/s40249-016-0180-3

[8] Petersen, Z., et al. (2013) Availability of HIV Prevention and Treatment Services for People Who Inject Drugs: Findings from 21 Countries. Harm Reduction Journal, 10, 1. https://doi.org/10.1186/1477-7517-10-13

[9] Esparza, J., et al. (2003) Estimation of "Needs" and "Probable Uptake" for HIV/AIDS Preventive Vaccines Based on Possible Policies and Likely Acceptance (A WHO/UNAIDS/ IAVI Study). Vaccine, 21, 2032-2041. https://doi.org/10.1016/S0264-410X(02)00775-2

[10] Kennedy, E.C., et al. (2013) Be Kind to Young People So They Feel at Home: A Qualitative Study of Adolescents' and Service Providers' Perceptions of Youth-Friendly Sexual and Reproductive Health Services in Vanuatu. BMC Health Services Research, 13, 1. https://doi.org/10.1186/1472-6963-13-455

[11] Rupali, P., et al. (2007) Prevention of Mother to Child Transmission of HIV Infection in Pacific Countries. Internal Medicine Journal, 37, 216-223. https://doi.org/10.1111/j.1445-5994.2007.01309.x

[12] DiStefano, A., et al. (2013) A Community-Based Participatory Research Study of HIV and HPV Vulnerabilities and Prevention in Two Pacific Islander Communities: Ethical Challenges and Solutions. Journal of Empirical Research on Human Research Ethics, 8, 68-78. https://doi.org/10.1525/jer.2013.8.1.68

[13] Ngoma, C.M., Roos, J. and Siziya, S. (2015) Knowledge about HIV and AIDS among Young Women. Open Journal of Nursing, 5, 558-565. https://doi.org/10.4236/ojn.2015.56059

[14] Coates, T.J., Richter, L. and Caceres, C. (2008) Behavioural Strategies to Reduce HIV Transmission: How to Make Them Work Better. The Lancet, 372, 669-684. https://doi.org/10.1016/S0140-6736(08)60886-7

[15] World Health Organization (2010) Towards Universal Access: Scaling up Priority HIV/AIDS Interventions in the Health Sector.

[16] Satcher, D., Hook, E.W. and Coleman, E. (2015) Sexual Health in America: Improving Patient Care and Public Health. JAMA, 314, 765-766. https://doi.org/10.1001/jama.2015.6831 
[17] Jamison, D.T., et al. (2006) Disease Control Priorities in Developing Countries. World Bank Publications.

[18] Qian, Z., Vermund, S.H. and Wang, N. (2005) Risk of HIV/AIDS in China: Subpopulations of Special Importance. Sexually Transmitted Infections, 81, 442-447. https://doi.org/10.1136/sti.2004.014258

[19] Vallely, A., et al. (2012) Intravaginal Practices and Microbicide Acceptability in Papua New Guinea: Implications for HIV Prevention in a Moderate-Prevalence Setting. BMC Research Notes, 5, 613. https://doi.org/10.1186/1756-0500-5-613

[20] Wilde, C. (2007) “Turning Sex into a Game”: Gogodala Men's Response to the AIDS Epidemic and Condom Promotion in Rural Papua New Guinea. Oceania, 77, 58-71. https://doi.org/10.1002/j.1834-4461.2007.tb00005.x

[21] Phongsavan, P., et al. (2005) Sexual Health Behaviours among Pacific Island Youth in Vanuatu, Tonga and the Federated States of Micronesia. Health Promotion Journal of Australia, 16, 144-150.

[22] Salud, M.C., Marshak, H., Natto, Z. and Montgomery, S. (2014) Exploring HIV-Testing Intentions in Young Asian/Pacific Islander (API) Women as It Relates to Acculturation, Theory of Gender and Power (TGP), and the AIDS Risk Reduction Model (ARRM). AIDS Care, 26, 642-647. https://doi.org/10.1080/09540121.2013.841836

[23] Johnson, K. (2016) Insights in Public Health: The Current State of Sexual Health Education in Hawaii Public Schools. Hawaii Journal of Medicine \& Public Health, 75, 82-86.

[24] Kevany, S., Gildea, A., Garae, C., Moa, S. and Lautusi, A. (2015) Global Health Diplomacy, National Integration, and Regional Development through the Monitoring and Evaluation of HIV/AIDS Programs in Papua New Guinea, Vanuatu, and Samoa. International Journal of Health Policy and Management, 4, 337-341. https://doi.org/10.15171/ijhpm.2015.89

[25] Zenner, D. and Russell, S. (2005) Sexually Transmitted Diseases and HIV/AIDS in Vanuatu: A Cause for Concern and Action. The New Zealand Medical Journal, 118, U1610.

[26] Griffen, V. (2006) Gender Relations in Pacific Cultures and Their Impact on the Growth and Development of Children.

[27] Caplan, P. (2013) The Cultural Construction of Sexuality. Routledge, Milton Park.

[28] Davis, J., Vyankandondera, J., Luchters, S. and Sim, D. (2016) Male Involvement in Reproductive, Maternal and Child Health: A Qualitative Study of Policymaker and Practitioner Perspectives in the Pacific. Reproductive Health, 13, 81. https://doi.org/10.1186/s12978-016-0184-2

[29] Nambambi, N.M. and Mufune, P. (2011) What Is Talked about When Parents Discuss Sex with Children: Family Based Sex Education in Windhoek, Namibia. African Journal of Reproductive Health, 15, 120-129.

[30] Burnard, P. and Gill, P. (2014) Culture, Communication and Nursing. Routledge, Milton Park.

[31] Ziller, E. and Lenardson, J. (2009) Rural-Urban Differences in Health Care Access Vary Across Measures. Research and Policy Brief, Maine Rural Health Research Center.

[32] Silal, S.P., Penn-Kekana, L., Harris, B., Birch, S. and McIntyre, D. (2012) Exploring Inequalities in Access to and Use of Maternal Health Services in South Africa. BMC Health Services Research, 12, 120. https://doi.org/10.1186/1472-6963-12-120

[33] Curry, C., Bunungam, P., Annerud, C. and Babona, D. (2005) HIV Antibody Seroprevalence in the Emergency Department at Port Moresby General Hospital, Papua New Guinea. Emergency Medicine Australasia, 17, 359-362. https://doi.org/10.1111/j.1742-6723.2005.00757.x

[34] Kaplan, J.E., et al. (2015) The Impact of HIV Care and Support Interventions on Key Out- 
comes in Low and Middle-Income Countries: A Literature Review. Journal of Acquired Immune Deficiency Syndromes, 68, S253-S256. https://doi.org/10.1097/QAI.0000000000000495

[35] Frisbie, W.P., Cho, Y. and Hummer, R.A. (2001) Immigration and the Health of Asian and Pacific Islander Adults in the United States. American Journal of Epidemiology, 153, 372380. https://doi.org/10.1093/aje/153.4.372

[36] Jenkins, C. (2005) HIV/AIDS in the Pacific. Asian Development Bank.

[37] Kang, E., Rapkin, B.D. and DeAlmeida, C. (2006) Are Psychological Consequences of Stigma Enduring or Transitory? A Longitudinal Study of HIV Stigma and Distress among Asians and Pacific Islanders Living with HIV Illness. AIDS Patient Care \& STDs, 20, 712-723. https://doi.org/10.1089/apc.2006.20.712

[38] Meiberg, A.E., Bos, A.E., Onya, H.E. and Schaalma, H.P. (2008) Fear of Stigmatization as Barrier to Voluntary HIV Counselling and Testing in South Africa. East African Journal of Public Health, 5, 49-54.

[39] Centers for Disease Control and Prevention (2011) National Diabetes Fact Sheet: National Estimates and General Information on Diabetes and Prediabetes in the United States. US Department of Health and Human Services, Centers for Disease Control and Prevention, Atlanta.

[40] Ramos, R.L., Green, N.L. and Shulman, L.C. (2009) Pasa la Voz: Using Peer Driven Interventions to Increase Latinas' Access to and Utilization of HIV Prevention and Testing Services. Journal of Health Care for the Poor and Underserved, 20, 29-35. https://doi.org/10.1353/hpu.0.0124

[41] Stone, A. (2002) Microbicides: A New Approach to Preventing HIV and Other Sexually Transmitted Infections. Nature Reviews Drug Discovery, 1, 977-985. https://doi.org/10.1038/nrd959

[42] Manns, M.P., et al. (2001) Peginterferon Alfa-2b plus Ribavirin Compared with Interferon Alfa-2b plus Ribavirin for Initial Treatment of Chronic Hepatitis C: A Randomised Trial. The Lancet, 358, 958-965. https://doi.org/10.1016/S0140-6736(01)06102-5

[43] Kirby, D. (2002) HIV Transmission and Prevention in Adolescents. HIV Insite Knowledge Base Chapter.

[44] Shapiro, S.L., Astin, J.A., Bishop, S. and Cordova, M. (2005) Mindfulness-Based Stress Reduction for Health Care Professionals: Results from a Randomized Trial. International Journal of Stress Management, 12, 164-176. https://doi.org/10.1037/1072-5245.12.2.164

[45] Lee, S.J. and Rotheram-Borus, M.J. (2009) Beyond the "Model Minority" Stereotype: Trends in Health Risk Behaviors among Asian/Pacific Islander High School Students. Journal of School Health, 79, 347-354. https://doi.org/10.1111/j.1746-1561.2009.00420.x

[46] Han, C.-S. (2009) Chopsticks Don't Make It Culturally Competent: Addressing Larger Issues for HIV Prevention among Gay, Bisexual, and Queer Asian Pacific Islander Men. Health \& Social Work, 34, 273-281. https://doi.org/10.1093/hsw/34.4.273

[47] DiStefano, A.S., et al. (2012) Contextualization of HIV and HPV Risk and Prevention among Pacific Islander Young Adults in Southern California. Social Science \& Medicine, 75, 699-708. https://doi.org/10.1016/j.socscimed.2012.04.011

[48] Linh, N.N., Huong, N.T. and Thuy, H.T. (2015) Evolving Trade Policy and the Trans-Pacific Partnership Agreement: Does It Threaten Vietnam's Access to Medicine and Its Progress towards Scaling up HIV Prevention, Treatment and Care? Global Public Health, 10, S149-S160. https://doi.org/10.1080/17441692.2014.981829

[49] Smith, G., Kippax, S., Aggleton, P. and Tyrer, P. (2003) HIV/AIDS school-Based Education in Selected Asia-Pacific Countries. Sex Education: Sexuality, Society and Learning, 3, 3-21. https://doi.org/10.1080/1468181032000052126 
[50] Reidpath, D. and Chan, K. (2005) HIV Discrimination: Integrating the Results from a Six-Country Situational Analysis in the Asia Pacific. AIDS Care, 17, 195-204. https://doi.org/10.1080/09540120500120278

[51] Fujita, M., et al. (2015) HIV Service Delivery Models towards "Zero AIDS-Related Deaths": A Collaborative Case Study of 6 Asia and Pacific Countries. BMC Health Services Research, 15, 176. https://doi.org/10.1186/s12913-015-0804-5

[52] Hahm, H.C., Song, I., Al Ozonoff, L. and Sassani, J. (2009) HIV Testing among Sexually Experienced Asian and Pacific Islander Young Women: Association with Routine Gynecologic Care. Women's Health Issues, 19, 279-288. https://doi.org/10.1016/j.whi.2009.05.001

[53] Wong, F.Y., Campsmith, M., Nakamura, G., Crepaz, N. and Begley, E. (2004) HIV Testing and Awareness of Care-Related Services among a Group of HIV-Positive Asian Americans and Pacific Islanders in the United States: Findings from a Supplemental HIV/AIDS Surveillance Project. AIDS Education and Prevention, 16, 440-447. https://doi.org/10.1521/aeap.16.5.440.48736

[54] Wong, F.Y., et al. (2012) HIV Testing and Management: Findings from a National Sample of Asian/Pacific Islander Men Who Have Sex with Men. Public Health Reports, 127, 186194.

[55] MacLaren, D., et al. (2013) Foreskin Cutting Beliefs and Practices and the Acceptability of Male Circumcision for HIV Prevention in Papua New Guinea. BMC Public Health, 13, 818. https://doi.org/10.1186/1471-2458-13-818

[56] Huang, Z.J., Wong, F., De Leon, J. and Park, R. (2008) Self-Reported HIV Testing Behaviors among a Sample of Southeast Asians in an Urban Setting in the United States. AIDS Education and Prevention, 20, 65-77. https://doi.org/10.1521/aeap.2008.20.1.65

[57] Meldrum, R.M., Liamputtong, P. and Wollersheim, D. (2015) Sexual Health Knowledge and Needs Young Muslim Women in Melbourne, Australia. International Journal of Health Services, 46, 124-140. https://doi.org/10.1177/0020731415615313

[58] Wong, N.S., Wong, K., Wong, P. and Lee, S. (2015) Incorporation of Estimated Community Viral Load before HIV Diagnosis for Enhancing Epidemiologic Investigations a Comparison between Men Who Have Sex with Men and Heterosexual Men in Hong Kong. Asia-Pacific Journal of Public Health, 27, 756-764. https://doi.org/10.1177/1010539515589340

[59] Operario, D., Nemoto, T., Ng, T., Syed, J. and Mazarei, M. (2005) Conducting HIV Interventions for Asian Pacific Islander Men Who Have Sex with Men: Challenges and Compromises in Community Collaborative Research. AIDS Education and Prevention, 17, 334-346. https://doi.org/10.1521/aeap.2005.17.4.334

[60] Choi, K.-H., Ayala, G., Paul, J., Boylan, R. and Gregorich, S.E. (2013) Social Network Characteristics and HIV Risk among African American, Asian/Pacific Islander, and Latino Men Who Have Sex with Men. Journal of Acquired Immune Deficiency Syndromes, 64, 496-501. https://doi.org/10.1097/QAI.0b013e3182a7ee52 


\section{Data Extraction Sheet}

\begin{tabular}{|c|c|c|c|c|}
\hline No. & Study/Article & Participants & Methods & Results \\
\hline 1. & $\begin{array}{l}\text { DiStefano et al. [12] } \\
\text { Year: } 2013 \\
\text { Country: USA } \\
\text { Types of study: Retrospectives }\end{array}$ & $\begin{array}{l}\text { Participants: } \\
\text { Young Adults/Parents } \\
\text { Number: } 95 \\
\text { Male: Not Stated } \\
\text { Female: Not Stated } \\
\text { Age: Not Stated }\end{array}$ & $\begin{array}{l}\text { Data Collection Tools: unknown } \\
\text { Sampling methods: unknown } \\
\text { Place: Community based }\end{array}$ & $\begin{array}{l}\text { Barriers } \\
\text { 1. Trust } \\
\text { 2. Religion cultural taboo } \\
\text { 3. Fear }\end{array}$ \\
\hline 2. & $\begin{array}{l}\text { Kang et al. [37] } \\
\text { Year: } 2006 \\
\text { Country: USA } \\
\text { Type of Study: Cross sectional }\end{array}$ & $\begin{array}{l}\text { Participants: HIV + API } \\
\text { Number: } 44 \\
\text { Male: } 36 \\
\text { Age: } 31 \text { - } 60 \text { yrs } \\
\text { Mean Age: } 44 \text {, SD: } 7.94 \\
\text { Female: } 5 \\
\text { Age: } 36 \text { - } 67 \text { yrs } \\
\text { Mean age: } 45 \text {, SD: } 12.82 \\
\text { Transgender: } 1 \\
\text { Age: } 47\end{array}$ & $\begin{array}{l}\text { Data Collection Tools: Interview } \\
\text { Sampling Method: } \\
\text { Non-random convenience sample } \\
\text { Place: Community based }\end{array}$ & $\begin{array}{l}\text { Barrier } \\
\text { 1. Stigma }\end{array}$ \\
\hline 3. & $\begin{array}{l}\text { Kennedy et al. [10] } \\
\text { Year: } 2013 \\
\text { Country: Vanuatu } \\
\text { Type of Study: Qualitative }\end{array}$ & $\begin{array}{l}\text { Participants: Adolescents, Policy } \\
\text { makers \& service providers } \\
\text { Number: } 341 \\
\text { Male: } 169 \\
\text { Female: } 172 \\
\text { Age: } 15 \text { - } 19 \text { yrs. }\end{array}$ & $\begin{array}{l}\text { Data collection Tools: Focus group, } \\
\text { Interview } \\
\text { Sampling Method: Purposive sample } \\
\text { Place: Community based }\end{array}$ & $\begin{array}{l}\text { Barriers } \\
\text { 1. Culture } \\
\text { 2. Taboos } \\
\text { 3. Lack of confidentiality } \\
\text { 4. Lack of Knowledge }\end{array}$ \\
\hline 4. & $\begin{array}{l}\text { Lee and Rotheram-Borus, [45] } \\
\text { Year: } 2009 \\
\text { Country: USA } \\
\text { Type of study: Cohort }\end{array}$ & $\begin{array}{l}\text { Participants: students } \\
\text { Number: } 13233 \\
\text { Female: Not Stated } \\
\text { Male: Not Stated } \\
\text { Age: below } 14 \text { to } 18+\end{array}$ & $\begin{array}{l}\text { Data Collection Tools: Questionnaire } \\
\text { Sampling Methods: Random sample } \\
\text { Place: School Based }\end{array}$ & $\begin{array}{l}\text { Barriers } \\
\text { 1. Parental communication }\end{array}$ \\
\hline 5. & $\begin{array}{l}\text { Han, [46] } \\
\text { Year: } 2009 \\
\text { Country: USA } \\
\text { Type of study: Descriptive }\end{array}$ & $\begin{array}{l}\text { Participants: Gay, Bisexual \& } \\
\text { Queer Asian Pacific Islander Men } \\
\text { Number: } 15 \\
\text { Male: } 15 \\
\text { Female: Not stated } \\
\text { Age } 18-50+\end{array}$ & $\begin{array}{l}\text { Data Collection Tools: } \\
\text { Focus group, Interview } \\
\text { Sampling Method: } \\
\text { Convenience Sampling } \\
\text { Place: Community based }\end{array}$ & $\begin{array}{l}\text { Barrier } \\
\text { 1. Racism } \\
\text { 2. Homophobia } \\
\text { 3. Low self esteem } \\
\text { 4. Negative role model }\end{array}$ \\
\hline 6. & $\begin{array}{l}\text { DiStefano et al. [47] } \\
\text { Year: } 2012 \\
\text { Country: USA } \\
\text { Type of study: Descriptive }\end{array}$ & $\begin{array}{l}\text { Participants: Young adults, } \\
\text { Parents, Health workers } \\
\text { Number: } 95 \\
\text { Female: Not Stated } \\
\text { Male: Not Stated }\end{array}$ & $\begin{array}{l}\text { Data Collection Tools: Focus group, } \\
\text { Interview } \\
\text { Sampling Method: Purposive } \\
\text { Place: Community based }\end{array}$ & $\begin{array}{l}\text { Barrier } \\
\text { 1. Misinformation } \\
\text { 2. Communication } \\
\text { 3. Perceptions } \\
\text { 4. Family shame } \\
\text { 5. Privacy } \\
\text { 6. Gender } \\
\text { 7. Parents role } \\
\text { 8. Religion }\end{array}$ \\
\hline 7. & $\begin{array}{l}\text { Linh et al. [48] } \\
\text { Year: } 2015 \\
\text { Country: Vietnam } \\
\text { Type of Study: Case design study }\end{array}$ & $\begin{array}{l}\text { Participants: Government } \\
\text { officials, Health workers, } \\
\text { business members, } \\
\text { civil society leaders } \\
\text { Number: } 20 \\
\text { Female: Not Stated } \\
\text { Male: Not Stated } \\
\text { Age: Not Stated }\end{array}$ & $\begin{array}{l}\text { Data Collection Tools: Interview } \\
\text { Sampling Method: Snowball } \\
\text { Place: Population base }\end{array}$ & $\begin{array}{l}\text { Barrier } \\
\text { 1. Cost } \\
\text { 2. Overprotected owner rights }\end{array}$ \\
\hline
\end{tabular}


Continued

Smith et al. [49]

Year: 2003

8. Countries: Brunei, Cambodia

China, Indonesia, PNG, etc.

Type of Study:

Descriptive study

Reidpath and Chan, [50]

Year: 2005

Country: China, India,

Indonesia, Philippines,

Thailand, Vietnam

Type of Study: Descriptive

Fujita et al. [51]

Year: 2015

10. Country: Cambodia, Myanmar, Nepal, PNG, Thailand, Vietnam Type of Study:

Descriptive

Hahm et al. [52]

Year: 2009

Country: USA

Type of study: Cohort

Wong et al. [53]

Year: 2004

12. Country: USA

Type of study: Descriptive study

Wong et al. [54]

Year: 2012

13. Country: USA

Type of study: Cross sectional Study

Rupali et al. [11]

Year: 2007

14. Country: 22 Pacific Island Countries (PNG, Palau, Fiji, Niue etc)

Type of Study: Descriptive

MacLaren et al. [55]

Year: 2013

Country: PNG

Type of Study: Descriptive

Huang et al. [56]

16. Year: 2008

Country: USA

Type of Study: Descriptive study

Meldrum et al., [57]

Year: 2016

17. Country: Australia

Type of Study: descriptive
Participants: Adults

Number: 150

Female: Not stated

Male: Not Stated

Age: Not Stated

Participants: 6 countries

Number: Not Stated

Female: Not Stated

Male: Not Stated

Age: Not Stated

Participants: Sex workers,

Drugs users

Age: 15 - 19 yrs.

Female: Not Stated

Male: Not Stated

Participants: Young adults

Number: 7576

Female: 7576

Age: 18 - 27 yrs.

Participants: HIV Patients

Numbers: 114

Age: $18+$ yrs.

Mean age: 38.7 yrs, SD: 9.3

Participants: API men sex men

Male: 445

Age: $\geq 18$ yrs,

Mean age: 30.7 SD: 10.3

Participants:

Health Care Providers

Number: Not Stated

Female: Not Stated

Male: Not Stated

Age: Not Stated

Participants: Staff \& Students

Number: 284

Male: 137

Female: 46

Age: $18+$ yrs

Participants: Non MSM adults

Number: 604

Age: 18 - 45 yrs.

Participants:

Young Muslim Women

Number: 11

Female: 11

Age: 18 - 25 yrs.
Data Collection Tools:

Questionnaires

Sampling Method: Snowball

Place: school based

Barriers

1. Perceptions

2. Lack of knowledge
Data Collection Tools: Interview,

Focus group

Sampling Method: Convenience sam-

pling

Place: Community Based

Data Collection Tools: Observation Sampling Method: Purposive

Place: Community Based

Barriers

1. Unavailability of services

Data Collection: Questionnaire Sampling Method: Cluster Sampling Place: School based

Barriers

1. Ethnicity

2. Unavailabe services

Data Collection Tools: Questionnaires

Sampling Method: Purposive

Place: Health care based

Barriers

1. Lack of awareness

2. Unavailability of services

Data Collection Tools: Screening Barriers

Test, Questionnaires

1. Language

Sampling Method: Purposive

2. Perceptions

Place: Community Based

3. Fear of disclosure

Data Collection Tool: Questionnaires Sampling Method: Purposive

Barriers

Place: Community based

1. Limited resources

2. Cost of Medications

Data Collection Tools: Focus groups

Questionnaires, Observation

Barriers

Sampling Method:

1. Time

Purposive Sampling

2. Cultural

Place: School based

Data Collection Tool: Questionnaire Sampling Method: Snowball

Place: Community based

Barriers

1. Lack of knowledge

2. Unavailability of

health personnel

Data Collection Tools: Interview Sampling Method:

Purposive sampling

Barriers

Place: Community based
1. Culture

2. Religion 
Zenner and Russell, [25]

18. Year: 2005

Country: Vanuatu

Type of Study: Descriptive

Wong et al. [58]

19. Year: 2013

Country: USA

Type of study: Retrospective

Vallely et al. [19]

Year: 2015

20. Country: Hong Kong

Type of study: Retrospective

Operario et al. [59]

21. Year: 2012

Country: PNG

Type of Study: Mixed method

Choi et al. [60]

Year: 2005

Country: USA

Type of Study: Descriptive
Participants: Government Officials, NGO workers

Number: 14

Female: Not Stated

Male: Not Stated

Age: Not Stated

Participants: Young adults

\& Parents

Number: 95

Female: Not Mention

Male: Not Mention

Age: Not Mention

Participants: Heterosexual

\& MSM male

Number: 2281

Male: MSM 1331

Heterosexual: 950

Participants: Young women

\& Men, Sex workers,

invulnerable individuals

Number: 28

Male: 12

[17 - 52 yrs, mean age 30]

Female: 6

[16 - 42 yrs, mean age 25]

Participants: API men sex men

Number: 1196

Male: Not reported

Age: $18-83$ yrs.
Data Collection Tools: Interview Sampling Method:

Purposive sampling

Place: Health care based

Barriers

1. Lack of awareness

2. inaccessible services

Data Collection Tools:

Questionnaires, Focus groups,

Sampling method: Unknown

Place: Community based

1. Community engagement

2. Gender mixed events

3. Online Training

Data Collection Tools:

Screening Test

Sampling Method:

Purposive Sample

Place: Community based

\section{Strategies}

1. Population level

viral load measures

Data Collection Tool: Interview Sampling Method: Purposive

Place: Community based

Strategies

1. Intravaginal Practices
Data Collection Tool: Questionnaire Sampling Method: Snowball Place: Community based
Strategies

1. Education

Submit or recommend next manuscript to SCIRP and we will provide best service for you:

Accepting pre-submission inquiries through Email, Facebook, LinkedIn, Twitter, etc.

A wide selection of journals (inclusive of 9 subjects, more than 200 journals)

Providing 24-hour high-quality service

User-friendly online submission system

Fair and swift peer-review system

Efficient typesetting and proofreading procedure

Display of the result of downloads and visits, as well as the number of cited articles

Maximum dissemination of your research work

Submit your manuscript at: http://papersubmission.scirp.org/

Or contact asm@scirp.org 